\title{
A bibliometric analysis of clinical study literature of traditional Chinese medicine therapies for smoking cessation
}

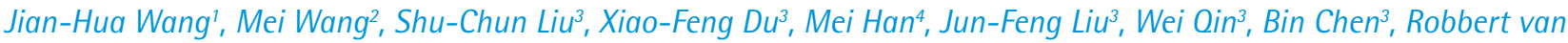 \\ Haselen $^{5}$, Jian-Ping Liư
}

\begin{abstract}
INTRODUCTION Traditional Chinese medicine (TCM) is commonly used for smoking cessation in China. The aim of this study is to perform a comprehensive literature search to identify clinical studies on TCM therapies for smoking cessation.

METHOds Publications of randomized controlled trials, controlled clinical studies, cohort studies, case-control studies, case series and case reports, reviews and cross-sectional studies on smoking cessation using TCM therapies were retrieved from seven databases from their inception to February 2017. The following data were extracted and analyzed: study type, year of publication, language, country or region, journals, participants, intervention and comparison, and outcome.

RESULTS In total, 260 publications on TCM therapies for smoking cessation were identified from 1980 to 2016, including 52 randomized clinical trials, 7 controlled clinical studies, 1 cohort study, 110 case series, 18 case reports, 50 narrative reviews, 17 systematic reviews, and 5 cross-sectional studies. Of these, $68.5 \%$ (178) were published in Chinese and the remaining published in English. Mainland China $(\mathrm{n}=129,49.6 \%)$ was the leading country in this field, followed by USA $(n=27,10.4 \%)$ and UK $(n=25,9.6 \%)$. A total of 36 645 participants from 40 countries with age ranging from 12 to 86 years were involved in 188 clinical studies (excluding reviews and cross-sectional studies). The most commonly reported therapies were auricular acupressure $(25,13.3 \%)$, body acupuncture $(14,7.4 \%)$, and body acupuncture plus auricular acupressure (14, 7.4\%). Composite outcomes were most frequently reported (110, 58.5\%). CONCLUSIONS A substantial number of clinical studies have been conducted and published on TCM therapy for smoking cessation, mainly focusing on acupuncture stimulation techniques. The findings suggest that future research should pay more attention to acupuncture for smoking cessation.
\end{abstract}

ABBREVIATIONS TCM: traditional Chinese medicine, RCTs: randomized controlled trials, CCTs: clinical controlled trials

\author{
AFFILIATION \\ 1 Science and Technology \\ Department, Liaoning \\ University of Traditional \\ Chinese Medicine, Shenyang \\ 110847, China \\ 2 School of Preclinical \\ Medicine, Liaoning University \\ of Traditional Chinese Medicine, \\ Shenyang 110847, China \\ 3 Medical Library, Liaoning \\ University of Traditional \\ Chinese Medicine, Shenyang \\ 110847, China \\ 4 Centre for Evidence-Based \\ Chinese Medicine, Beijing \\ University of Traditional \\ Chinese Medicine, 11 Bei San \\ Huan Dong Lu, Chaoyang \\ District, Beijing 100029, China \\ 5 International Forum on \\ Integrative Medicine \\ CORRESPONDENCE TO \\ Jian-Ping Liu. Centre for \\ Evidence-Based Chinese \\ Medicine, Beijing University of \\ Traditional Chinese Medicine, \\ 11 Bei San Huan Dong Lu, \\ Chaoyang District, Beijing \\ 100029, China. E-mail: Liujp@ \\ bucm.edu.cn
}

\section{KEYWORDS}

bibliometric analysis, clinical studies, smoking cessation, traditional Chinese medicine therapy

Received: 27 July 2017

Revised: 6 March 2018

Accepted: 6 March 2018

\section{INTRODUCTION}

Smoke from cigarettes contains a variety of harmful substances $^{1-3}$ and smoking is one of the principal causes of chronic obstructive pulmonary disease, cancer, atherosclerotic cardiovascular disease and cerebrovascular disease $\mathrm{e}^{4,5}$, which are the most 
common causes of morbidity and mortality ${ }^{6-8}$. The World Health Organization (WHO) reports that tobacco-use causes the death of about 6 million people worldwide every year ${ }^{9}$. More than 5 million of these deaths are associated directly with the use of tobacco, with more than 600000 of these deaths corresponding to non-smokers exposed to secondhand smoke ${ }^{9}$. Smoking addiction is a complex problem, involving physical, psychological, social and other factors ${ }^{10}$, mainly due to nicotine, the psychoactive substance contained in cigarettes ${ }^{11,12}$. The development of smoking-related diseases and the associated risk of death significantly decrease in smokers who quit smoking ${ }^{13,14}$. Under the guidance of WHO, countries worldwide are taking active measures against smoking ${ }^{15,16}$.

The most common recommended approaches to quitting smoking include nicotine replacement therapy, antidepressants and psychological support $^{17-29}$. Despite the high cost, the effectiveness of these approaches is limited and side effects (such as anorexia, nausea, constipation, headache, drowsiness or insomnia) can occur ${ }^{30,31}$. Therefore, new approaches that could help smokers to quit smoking are warranted. Traditional Chinese Medicine (TCM) therapy is widely used to aid smoking cessation, and because of its relative safety, low cost and claimed effectiveness, it has attracted increasing attention worldwide $^{32,33}$. The application of TCM therapy to smoking cessation has a long history in China. Its aim is to inhibit the craving for cigarettes and to alleviate withdrawal symptoms ${ }^{34}$. There is widespread interest in TCM therapy for smoking cessation, especially the use of acupuncture which has been investigated in a series of clinical studies. Despite this, the effectiveness of TCM therapy for smoking cessation is still controversial.

We are, therefore, committed to obtaining insights on the role of TCM therapy in the field of smoking cessation. This comprehensive bibliometric analysis aims to provide an overview of the status of TCM therapy as an intervention for smoking cessation worldwide. We intend to identify, develop and offer appropriate evidence-based TCM approaches to help people to quit smoking, as well as to provide a framework for further evaluating the efficacy of the most promising TCM approaches for smoking cessation.

\section{METHODS}

\section{Search strategy}

We searched five Chinese and two English language electronic databases (see Additional file 1 for details). With two library staff members (SCL and JFL), we developed the search terms and conducted literature searches. In order not to miss relevant articles, we decided not to set other limitations on the searching.

\section{Eligibility criteria}

We included all types of clinical studies: randomized controlled trials (RCTs), clinical controlled trials (CCTs), cohort studies, case-control studies, case series and case reports. Descriptive epidemiological studies (cross-sectional surveys), systematic reviews and traditional reviews on TCM therapies for smoking cessation were also included. Editorials and letters to the editor were excluded. When the same data were published more than once, we chose those that provided more comprehensive information. We considered documents to be eligible those which aimed at evaluating the therapeutic effect or safety of smoking cessation by TCM therapies. Those studies that were conducted to study mechanisms of action were not included.

\section{Types of interventions}

For clinical studies, we placed no limitations on the types of TCM therapies, such as acupuncture, acupressure, massage, herbal formulae, herbal extracts, plaster on acupuncture points, qi gong, Tai chi, and so on. In fact, we intended to understand the overall view of the therapeutic effect of all types of TCM therapies in the field of smoking cessation. Monotherapy (acupuncture, qi gong, etc.) and multiple therapies that combined TCM therapy with other interventions (acupuncture plus auricular acupressure, acupuncture plus nicotine replacement therapy, etc.) were all included.

\section{Comparisons}

For controlled clinical studies, including RCTs, CCTs, cohort studies and case-control studies, the control interventions were: no treatment, sham treatment, waiting list, other treatment, and combined therapy. The control intervention of some studies was a notreatment control ${ }^{35}$ or waiting list ${ }^{36}$. Some studies utilized sham acupuncture or placebo as the control 
intervention ${ }^{37,38}$. Single and combined therapies, such as nicotine replacement therapy ${ }^{39}$, behavioral therapy $^{36}$, TCM therapy plus counseling ${ }^{40}$, and so on, are also often applied as control interventions.

\section{Data extraction and analysis}

One author (XFD) imported the retrieved bibliography citations into NoteExpress (3.2.0.6976), and duplicates were deleted. JHW first screened the articles that clearly did not meet the inclusion criteria based on the reading of titles and abstracts. Next, two review authors ( JHW and $\mathrm{MH}$ ) selected eligible articles by reading the full text independently. JPL was responsible for resolving differences and contradictions in the screening process of the two authors, and for checking the eligibility of included articles. Three review authors ( JHW, WQ, BC) extracted data from the included studies with a self-developed electronic data extraction form using the public domain software package Epidata (version 3.1). In case of disagreement, a consensus was reached by discussion with JPL. The extracted variables included: publication characteristics, study design, demographic characteristics, intervention details, control treatment details, and clinical outcomes.

The extracted data were imported into SPSS (release 20.0, IBM, Armonk, NY, USA) and Microsoft Excel (version 12.3.5, Microsoft, Redmond, WA, USA), which were used for the statistical analysis and to describe the characteristics of the data. Categorical variables were represented by frequencies and percentages, while continuous variables were reported as means and standard deviations.

\section{RESULTS}

\section{General description of included literature}

A total of 260 records were included and analyzed in this study (Figure 1), of these $178(68.5 \%)$ articles were published in Chinese, while $82(31.5 \%)$ articles were in English. Journal articles (244, 93.8\%) were the most frequent publication type, followed by dissertations $(8,3.1 \%)$, and conference full text papers $(6,2.3 \%)$. Most of the studies were conducted by universities or medical colleges $(106,40.8 \%)$. Hospitals $(96,36.9 \%)$ also played an important role in studies related to smoking cessation using TCM therapy, followed by research institutes $(30,11.5 \%)$
Fig 1. The flowchart of including and existing studies

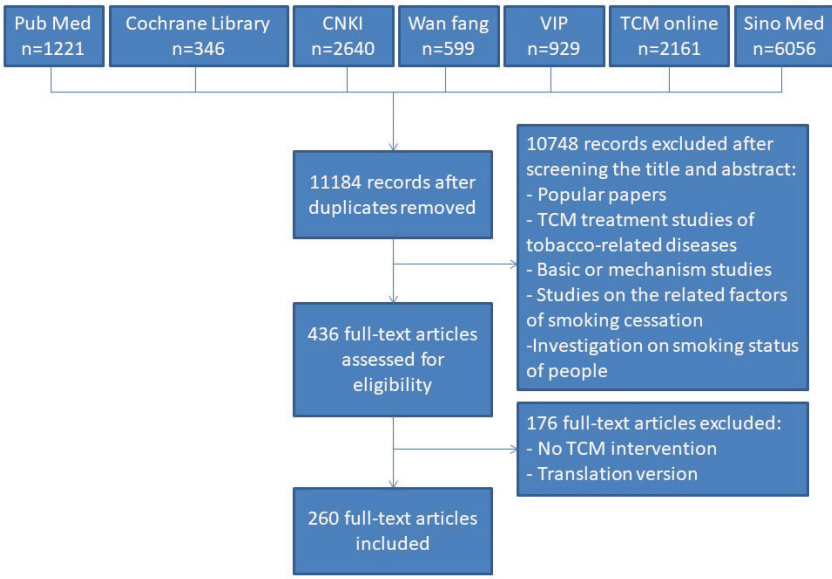

and associations $(4,1.9 \%)$. Other clinical settings (16, $6.2 \%$ ) in which smoking cessation studies were carried out included: clinics, community health centers, nursing homes, companies, and foreign aid medical teams. Seven $(2.7 \%)$ articles provided no information about the institution. Among the 260 articles, 205 (78.8\%) studies did not report whether they had been funded, $52(20 \%)$ studies received financial support, and $3(1.2 \%)$ did not have any financial aid.

Annual publications on smoking cessation using TCM therapy are summarized in Figure 2. The earliest publication year was 1980 , at that time there was just one article produced. The first study was a case series conducted by a Chinese doctor in West African Senegal. From 1980 to 2016, the annual number of publications related to smoking cessation using TCM therapy increased slightly, with a peak of 14 in 2006. In terms of the number of publications, there was a significant decline until 2008. Since 2009 and 2010 , there has been a large increase in publications, peaking in 2013. From 2013 to 2016, the annual

Fig 2. Annual number of publications for smoking cessation using TCM therapy

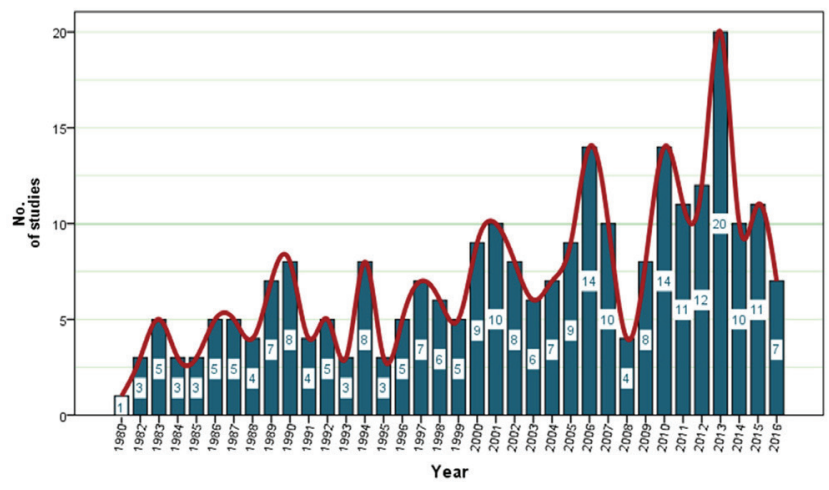


number of publications decreased significantly. The long-term trend is a gradual increase in the number of publications.

Table 1. Distribution of countries where the studies of smoking cessation using TCM therapies were performed

\begin{tabular}{|c|c|c|c|c|c|c|}
\hline Country & \multirow{2}{*}{$\begin{array}{r}\text { Frequeney } \\
129\end{array}$} & $\begin{array}{r}\text { Percentage } \\
\% \text { N } 260\end{array}$ & \multirow{2}{*}{\multicolumn{4}{|c|}{$\begin{array}{l}\text { in other countries were conducted by Chinese who } \\
\text { were providing medical aid abroad, including twelve } \\
\text { African countries, Austria, Germany, Republic of }\end{array}$}} \\
\hline Mainland China & & 49.6 & & & & \\
\hline USA & 27 & 10.4 & Korea, Ku & vait, Lao $\mathrm{Pe}$ & eople's Den & ocratic Republic, \\
\hline UK & 26 & 10.0 & Portugal, $\mathrm{R}$ & ssian Fede & ration, Sing & pore, Switzerland, \\
\hline Republic of Korea & 9 & 3.5 & Thailand, ] & urkey, UAF & $\mathrm{E}, \mathrm{UK}$ and $\mathrm{t}$ & ie USA. Only one \\
\hline Taiwan, China & 7 & 2.7 & study was & collabora & ation condu & cted in mainland \\
\hline Australia & 5 & 1.9 & China and & Taiwan, Chi & ina (Table 1 & \\
\hline Malta & 4 & 1.5 & Active au & thors in pul & blishing arti & les about smokin \\
\hline France & 3 & 1.2 & cessation $\mathrm{u}$ & ing TCM t & therapy are & hown in Table 2 \\
\hline Germany & 3 & 1.2 & with Whi & being the & & contributor wit \\
\hline Hong Kong, China & 3 & 1.2 & with Wh & being the & most prolif & contributor with \\
\hline Singapore & 3 & 1.2 & 10 article & Ten active & authors wer & Chinese, and the \\
\hline Switzerland & 3 & 1.2 & other activ & authors $\mathrm{n}$ & vere from $\mathrm{R}$ & public of Korea, \\
\hline Turkey & 3 & 1.2 & France, US & 1 and Taiws & an, China. & \\
\hline No record & 3 & 1.2 & Table 3 & ranks the & journals b & $y$ the number of \\
\hline Russian Federation & 2 & 0.8 & publicatior & s. Chinese & Acupunctu & e \& Moxibustion \\
\hline Namibia & 2 & 0.8 & outranked & ther journa & als with $21 \mathrm{p}$ & ablications. Of the \\
\hline Thailand & 2 & 0.8 & top $10 \mathrm{acti}$ & journals, & 7 were $\mathrm{Chi}$ & ese journals, an \\
\hline UAE & 2 & 0.8 & 3 were in & rish & & 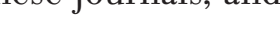 \\
\hline Niger & 2 & 0.8 & & & & \\
\hline Senegal & 2 & 0.8 & & & & \\
\hline Arabia & 1 & 0.4 & Table 2. Fir: & t authors $w$ & ho producec & wo or more \\
\hline Austria & 1 & 0.4 & articles on & moking ces & sation using & M therapies \\
\hline Brazil & 1 & 0.4 & & & & \\
\hline Canada & 1 & 0.4 & First author & $\begin{array}{l}\text { Irucie } \\
\text { frequency }\end{array}$ & $\%$ N 260 & Country \\
\hline Central African Republic & 1 & 0.4 & White AR & 10 & 3.8 & UK \\
\hline $\begin{array}{l}\text { United Republic of Tanzania } \\
\text { Italy }\end{array}$ & $\begin{array}{l}1 \\
1\end{array}$ & $\begin{array}{l}0.4 \\
0.4\end{array}$ & Huang JM & 3 & 1.2 & Mainland China \\
\hline Kuwait & 1 & 0.4 & Wang YY & 3 & 1.2 & Mainland China \\
\hline Lao People's Democratic & 1 & 0.4 & Chae $Y$ & 2 & 0.8 & Republic of Korea \\
\hline Republic & & & Clavel F & 2 & 0.8 & France \\
\hline Netherlands & 1 & 0.4 & Sood A & 2 & 0.8 & USA \\
\hline Morocco & 1 & $\begin{array}{l}0.4 \\
0.4\end{array}$ & Yeh ML & 2 & 0.8 & Taiwan, China \\
\hline $\begin{array}{l}\text { Norway } \\
\text { Portugal }\end{array}$ & $\begin{array}{l}1 \\
1\end{array}$ & $\begin{array}{l}0.4 \\
0.4\end{array}$ & Cui M & 2 & 0.8 & Mainland China \\
\hline Mauritius & 1 & 0.4 & Fang YA & 2 & 0.8 & Mainland China \\
\hline Taiwan, China and & 1 & 0.4 & Gu ZR & 2 & 0.8 & Mainland China \\
\hline Mainland China & & & Lei ZO & 2 & 0.8 & Mainland China \\
\hline Burkina Faso & 1 & 0.4 & $\mathrm{Li} \mathrm{HB}$ & 2 & 0.8 & Mainland China \\
\hline Mali & 1 & 0.4 & Liu C & 2 & 0.8 & Mainland China \\
\hline $\begin{array}{l}\text { Nigerıa } \\
\text { Nigeria and Egypt }\end{array}$ & $\begin{array}{l}1 \\
1\end{array}$ & $\begin{array}{l}0.4 \\
0.4\end{array}$ & Wang XJ & 2 & 0.8 & Mainland China \\
\hline Togo & 1 & 0.4 & Wang YX & 2 & 0.8 & Mainland China \\
\hline Total & 260 & 100.0 & Total & 40 & 15.4 & \\
\hline
\end{tabular}

The top seven countries, in which studies were carried out, were mainland China $(129,49.6 \%)$, USA $(27,10.4 \%)$, UK $(25,9.6 \%)$, Republic of Korea (9, $3.5 \%)$, Taiwan, China (7, 2.7\%), Australia (5, 1.9\%), Malta $(4,1.5 \%)$, followed by 31 other countries.

Nearly half of the 260 articles were performed in mainland China, and another 40 studies performed in other countries were conducted by Chinese who ere providing medical aid abroad, including twelve African countries, Austria, Germany, Republic of Korea, Kuwait, Lao People's Democratic Republic, Portugal, Russian Federation, Singapore, Switzerland, study was a collaboration conducted in mainland ina and Taiwan, China (Table 1). essation using TCM therapy are shown in Table 2, ith White being the most prolific contributor with other active authors were from Republic of Korea, Table 3 ranks the journals bo publications. Chinese Acupuncture \& Moxibustion outranked other journals with 21 publications. Of the p 10 active journals, 7 were Chinese journals, and 0 articles. Ten active authors were Chinese, and the

.




\section{Study types}

Figure 3 illustrates that the great majority of the literature consists of case series $(110,42.3 \%)$, followed by RCTs $(52,20.0 \%)$, traditional reviews

Table 3. Top ten most active journals in the field of smoking cessation applying TCM therapy

\begin{tabular}{|c|c|c|c|}
\hline Journal & Frequency & $\begin{array}{l}\text { Percentage } \\
\% \text { N } 260\end{array}$ & Language \\
\hline $\begin{array}{l}\text { Chinese Acupuncture \& } \\
\text { Moxibustion }\end{array}$ & 21 & 8.1 & Chinese \\
\hline $\begin{array}{l}\text { Shaanxi Journal of } \\
\text { Traditional Chinese } \\
\text { Medicine }\end{array}$ & 7 & 2.7 & Chinese \\
\hline $\begin{array}{l}\text { Journal of Clinical } \\
\text { Acupuncture and } \\
\text { Moxibustion }\end{array}$ & 7 & 2.7 & Chinese \\
\hline $\begin{array}{l}\text { Shanghai Journal } \\
\text { of Acupuncture and } \\
\text { Moxibustion }\end{array}$ & 6 & 2.3 & Chinese \\
\hline $\begin{array}{l}\text { Journal of Traditional } \\
\text { Chinese Medicine }\end{array}$ & 6 & 2.3 & Chinese \\
\hline Am J Chin Med & 5 & 1.9 & English \\
\hline $\begin{array}{l}\text { Evid Based } \\
\text { Complement Alternat } \\
\text { Med }\end{array}$ & 5 & 1.9 & English \\
\hline $\begin{array}{l}\text { J Altern Complement } \\
\text { Med }\end{array}$ & 5 & 1.9 & English \\
\hline $\begin{array}{l}\text { Journal of Liaoning } \\
\text { University of } \\
\text { Traditional Chinese } \\
\text { Medicine }\end{array}$ & 5 & 1.9 & Chinese \\
\hline $\begin{array}{l}\text { Journal of Sichuan of } \\
\text { Traditional Chinese } \\
\text { Medicine }\end{array}$ & 5 & 1.9 & Chinese \\
\hline Total & 72 & $27.7 \%$ & \\
\hline
\end{tabular}

Fig 3. The distribution of study types

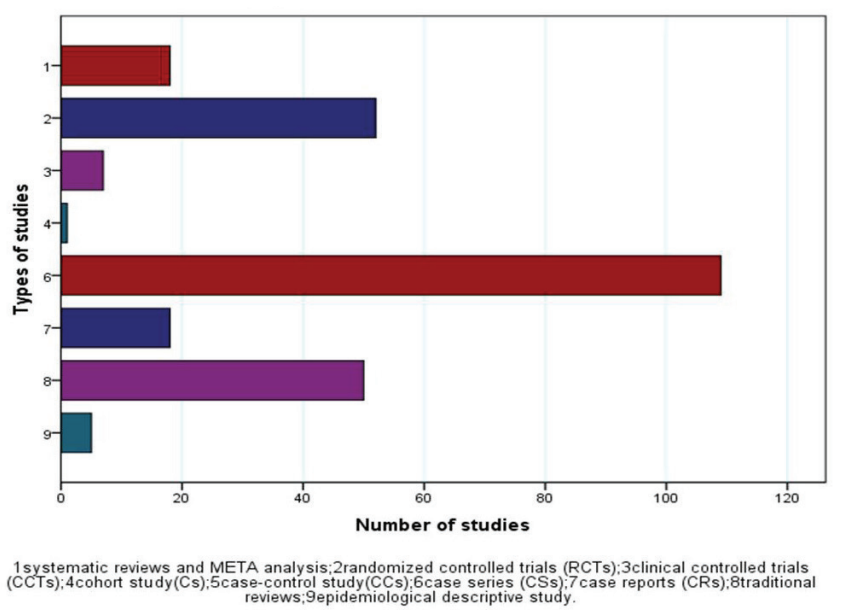

(50,19.2\%), individual case reports $(18,6.9 \%)$, systematic reviews $(17,6.5 \%)$ and CCTs $(7,2.7 \%)$. Cross-sectional descriptive epidemiological studies $(5,1.9 \%)$ accounted for less of the data and cohort studies were the least common $(1,0.3 \%)$.

Case series was the earliest type of study ${ }^{41}$, which was reported in the Journal of Traditional Chinese Medicine, in Chinese, with smoking cessation rate reaching $90.95 \%$ after intervention by body acupuncture and auxiliary ear acupoint buried needle. Case series was also the most frequently applied study type for investigating the effectiveness of TCM for smoking cessation, and it was particularly popular in China. Of the case series, 103 were conducted by Chinese, while only 7 were conducted by other countries. Compared to RCTs, case series are easier to complete. The first RCTs ${ }^{42}$ about smoking cessation using TCM therapy were published in Am J Chin Med in 1982, conducted in the USA comparing the smoking cessation efficacy of real ear acupuncture (RA) and sham ear acupuncture. Most of the systematic reviews (16/17) were published in English journals. The British Journal of General Practice reported the first meta analysis of studies on the effect of acupuncture on addiction ${ }^{43}$.

\section{Participants}

There were 36645 participants in the 188 clinical studies, excluding the 67 reviews and 5 descriptive epidemiological studies. The largest sample size was 8803 (a case series conducted in Guangxi China with a reported rate of smoking cessation of $95.0 \%$, while the smallest study had an $\mathrm{N}=1$ (case report). In all, $21990(60.0 \%)$ were male and 14655 (40.0\%) were female. Of the 188 clinical studies, only 11 studies reported a detailed ethnic distribution of participants. The analysis of extracted data indicated that the youngest participant was 12 years old and the oldest 86 years. The duration of regular active or passive smoking of all participants varied from 3 months to 70 years. There was a wide variation in the number of cigarettes consumed daily (3-100).

\section{Therapy category}

A total of $173(92.0 \%)$ publications of 188 clinical studies did not report any information about diagnostic criteria of tobacco dependence. Only $22(11.7 \%)$ studies reported the use of syndrome 
differentiation to guide treatment. Regarding the treatment principle of traditional Chinese medicine, $34(18.1 \%)$ clinical studies described it in detail, including the treatment principle of Tiao Li Fei Qi, Shu Gan Jian Pi, Zhen Jing An Shen. Overall, 142 $(75.5 \%)$ of the 188 studies clearly recorded the operational steps and specifications of the treatment approach. Details on the course of treatment could not be found in $9(4.8 \%)$ articles, and another 11 (5.9\%) articles lacked detail on the treatment sessions. In the remaining 168 studies, the average duration of treatment varied from 10 minutes to 12 weeks. Table 4 illustrates the varied nature of TCM interventions employed to aid smoking cessation.

Table 4. Number of different categories of therapies in clinical studies

\begin{tabular}{|c|c|c|}
\hline Calcgories & Intervention & Frequeney \\
\hline \multirow{23}{*}{$\begin{array}{l}\text { Single } \\
\text { treatment }\end{array}$} & auricular acupressure & 25 \\
\hline & body acupuncture & 14 \\
\hline & auricular acupuncture & 5 \\
\hline & embedded needling at auricular acupoint & 5 \\
\hline & qigong & 5 \\
\hline & auricular electroacupuncture & 4 \\
\hline & auricular acupoint stimulation using lasers & 4 \\
\hline & herb formula & 4 \\
\hline & Chinese herb extracts & 4 \\
\hline & auricular acupoint stimulation using electricity & 2 \\
\hline & acupoint stimulation using lasers & 2 \\
\hline & acupoint application & 2 \\
\hline & herb tea & 2 \\
\hline & body electroacupuncture & 1 \\
\hline & scalp acupuncture & 1 \\
\hline & Dai Zhen Gao & 1 \\
\hline & acupoint stimulation using electricity & 1 \\
\hline & acupoint embedded line & 1 \\
\hline & acupuncture and moxibustion & 1 \\
\hline & tea filters & 1 \\
\hline & treatment at Tian Mei acupoint & 1 \\
\hline & standing pile & 1 \\
\hline & Inedia & 1 \\
\hline \multirow{13}{*}{$\begin{array}{l}\text { Two } \\
\text { types of } \\
\text { treatment } \\
\text { combined }\end{array}$} & body acupuncture + auricular acupressure & 14 \\
\hline & body acupuncture + embedded needling at auricular acupoint & 5 \\
\hline & auricular acupressure + psychological intervention & 4 \\
\hline & body electroacupuncture + auricular acupressure & 4 \\
\hline & body acupuncture + auricular acupuncture & 3 \\
\hline & auricular acupuncture + auricular acupressure & 3 \\
\hline & body acupressure + auricular acupressure & 2 \\
\hline & auricular electroacupuncture + embedded needling at & \\
\hline & auricular acupoint & 2 \\
\hline & auricular electroacupuncture + auricular acupressure & 2 \\
\hline & auricular acupressure + multimedia instruction & 2 \\
\hline & body acupuncture + moxibustion & 1 \\
\hline & body acupuncture + body electroacupuncture & 1 \\
\hline
\end{tabular}


Table 4. Continued

\begin{tabular}{|c|c|}
\hline Categories & Intervention \\
\hline \multirow{24}{*}{$\begin{array}{l}\text { Two } \\
\text { types of } \\
\text { treatment } \\
\text { combined }\end{array}$} & body acupuncture + bloodletting \\
\hline & body acupuncture + scalp acupuncture \\
\hline & body acupuncture + wrist-ankle acupuncture \\
\hline & body acupuncture + smoking therapy \\
\hline & body acupuncture + psychological intervention \\
\hline & body acupuncture + body acupressure \\
\hline & body electroacupuncture + cupping \\
\hline & body electroacupuncture + embedded needling at body acupoint \\
\hline & body acupoint massage + auricular acupoint massage \\
\hline & auricular acupuncture + embedded needling at auricular acupoint \\
\hline & auricular acupuncture + the Internet-assisted smoking cessation program \\
\hline & auricular acupressure + auricular acupoint massage \\
\hline & auricular acupressure + scraping \\
\hline & auricular acupressure + body acupoint massage \\
\hline & auricular acupressure + body acupressure \\
\hline & auricular acupressure + decreasing smoke consumption method gradually \\
\hline & embedded needling at auricular acupoint + herb formula \\
\hline & auricular acupoint stimulation using lasers + body acupoint stimulation \\
\hline & using lasers \\
\hline & scalp acupuncture + eye acupuncture \\
\hline & Acupoint application + psychological intervention \\
\hline & Acupoint application + varenicline tartrate tables \\
\hline & Chinese herb extracts + smoking cessation message \\
\hline & Chinese herb extracts + behavioral intervention \\
\hline \multirow{4}{*}{$\begin{array}{l}\text { Three } \\
\text { types of } \\
\text { treatment } \\
\text { combined }\end{array}$} & body acupuncture + herb formula + line point moxibustion of Zhuang medicine \\
\hline & body electroacupuncture + auricular acupuncture + auricular acupressure \\
\hline & body acupuncture + auricular acupuncture + embedded needling \\
\hline & at auricular acupoint \\
\hline
\end{tabular}

body acupuncture + body acupoint massage + auricular acupressure 1

body acupuncture + auricular acupressure + herb tea 1

body acupuncture + embedded needling at auricular acupoint + acupoint stimulation using lasers 1

body acupuncture + embedded needling at auricular acupoint + herb tea 1

body acupuncture + auricular acupuncture + auricular acupressure 1

body acupuncture + auricular acupuncture + nicotine replacement therapy (NRT) 1

body acupuncture + auricular acupuncture + scalp acupuncture $\quad 1$

body acupuncture + bloodletting + decreasing smoke consumption method gradually 1

body acupuncture + manipulation + psychological intervention 1

body acupuncture + auricular electroacupuncture + auricular acupressure 1

body electroacupuncture + auricular acupressure + body acupuncture 1

auricular acupressure + NRT + team support $\quad 1$

auricular acupressure + herb cigarette + basic management intervention 1

auricular acupressure + acupoint application + herb tea 1

auricular acupuncture + body acupuncture + smoking cessation education 1

scalp acupuncture + nasal acupuncture + NRT 1

plum-blossom needling + ear acupressure + acupoint injection 1 
Table 4. Continued

\begin{tabular}{|c|c|c|}
\hline Categories & Intervention & Frequency \\
\hline \multirow{4}{*}{$\begin{array}{l}\text { Four } \\
\text { types of } \\
\text { treatment } \\
\text { combined }\end{array}$} & body acupuncture + auricular acupressure + auricular electroacupuncture + Chinese patent medicine & 1 \\
\hline & body acupuncture + auricular acupressure + herb tea + psychological intervention & 1 \\
\hline & body acupuncture + auricular acupressure + auricular acupuncture + herb tea & 1 \\
\hline & body acupuncture + auricular acupressure + body electroacupuncture + psychological intervention & 1 \\
\hline \multirow{4}{*}{$\begin{array}{l}\text { More } \\
\text { than four } \\
\text { types of } \\
\text { treatment } \\
\text { combined }\end{array}$} & $\begin{array}{l}\text { auricular acupressure }+ \text { western medicine }+ \text { psychological intervention }+ \text { health education }+ \text { administrative } \\
\text { interference }+ \text { multimedia }\end{array}$ & 1 \\
\hline & $\begin{array}{l}\text { acupuncture + individualized counseling + nicotine replacement therapy + stress management + behavior } \\
\text { modification }\end{array}$ & 1 \\
\hline & $\begin{array}{l}\text { auricular acupoint stimulation using electricity + auricular acupoint stimulation using lasers + nasal } \\
\text { acupoint stimulation using electricity + nasal acupoint stimulation using lasers + standardized consulting }\end{array}$ & 1 \\
\hline & the Zhuang medicine comprehensive treatment of acupuncture treatment & 1 \\
\hline
\end{tabular}

\section{Outcomes}

Of the 188 clinical studies, 111 (59.0\%) reported follow-up after the therapy ranging from 26 hours $^{44}$ to 5 years ${ }^{45}$. Seventy $(37.2 \%)$ clinical studies failed to report the main efficacy criteria. The TCM therapy effectiveness was reported comprehensively in 111 $(59.0 \%)$ studies, smoking cessation rate was reported in $77(41.0 \%)$, smoking craving in $24(12.8 \%)$, nicotine dependence scale in $19(10.1 \%)$, changes in withdrawal symptoms in $33(17.6 \%)$, decrease in daily cigarette consumption in $47(25.0 \%)$, change in the taste of cigarettes in $25(13.3 \%)$, and laboratory parameters in 33 (17.6\%). Five (2.7\%) studies included assessment of quality of life. Fortyone $(21.8 \%)$ studies focused on the safety of the therapy, including adverse events and/or adverse drug reactions. Two studies (1.1\%) reported health economic data.

\section{DISCUSSION}

The present study identified and comprehensively analyzed 260 publications of TCM therapy for smoking cessation. Mainland China was the main country that investigated TCM for smoking cessation. On the other hand, our study also showed that TCM therapy is widely accepted and used in the field of smoking treatment throughout the world. However, international collaboration on this topic is rare. Systematic reviews are important in the field of efficacy evaluation. A systematic review of clinical trials ${ }^{46}$ published in 2014 concluded that there was not enough evidence indicating acupuncture was effective in smoking cessation. This finding is inconsistent with a large body of outcome data on clinical practice.

As a bibliometric study, we tried to identify all available clinical evidence on TCM therapies for smoking cessation. Therefore, all types of experimental and observational studies, review articles and descriptive epidemiological studies related to smoking cessation applying TCM therapy were retrieved. We found a predominance of case series. The number of RCTs, considered by many to be the gold standard for clinical efficacy, was less than half the number of case series. This may be one of the reasons why the efficacy of TCM therapy for smoking cessation is not widely recognized globally. Targeting the individual treatment characteristics and current status of clinical research in TCM, a proposal for evidence grading that focused not only on RCTs but also on cohort studies, case-control studies, case series was suggested ${ }^{47}$, in order to reflect the efficacy of TCM more objectively and correctly.

Due to the diversity and flexibility of TCM therapy, smoking cessation therapy was applied in different ways according to the actual situation of the smokers, the stage of the smoking cessation process ${ }^{48}$ and clinical experience of the researchers. This included single TCM therapies, as well as various treatment combinations, including those with western therapy such as nicotine replacement therapy. The application of TCM syndrome differentiation made the treatment more complicated. It is difficult to develop a unified, repeatable TCM therapy for smoking cessation. This undoubtedly hinders the spread of TCM therapy for smoking cessation and makes it difficult to carry out a 
systematic review on the beneficial effect of smoking cessation using TCM therapy. An additional table file shows this in more detail [see Additional file 2].

This bibliometric analysis has several limitations, including selection of databases and language restrictions. At present, there is a variety of databases, specialized or generalized. Due to resource constraints, we could not retrieve all the databases, especially some English databases, such as Google Scholar, and the acupuncture academic professional database, which may have led to missing publications. Moreover, limiting our analysis to articles published in Chinese and English, means that we missed publications in other languages, such as French, Korean, Japanese, German, Russian, etc.

\section{CONCLUSIONS}

To our knowledge, the available data related on TCM therapy for smoking cessation has been comprehensively described for the first time based on a systematic bibliometric approach. Our study revealed the characteristics of the literature on TCM therapy for smoking cessation. It included a general description of the available literature, study types, interventions, participants and outcome assessments. This provides a useful overview for researchers and clinicians with an interest in the topic of smoking cessation. The design types of research used in the area of smoking cessation using TCM may provide a reference for future research on evidence evaluation on this topic. The analysis of all kinds of interventions, especially acupuncture, may provide a reference for the selection of interventions for clinical practice or future research of addiction.

Whilst mainland China is the leading country to conduct research on TCM therapy, many other countries are also active in this field. Especially, acupuncture therapy has been applied to help smokers quit smoking worldwide. Despite the importance of smoking cessation using TCM therapy, the extent of international collaboration on this topic is very small. This paper may help to foster further cooperation.

\section{REFERENCES}

1. Brewer NT, Morgan JC, Baig SA, Mendel JR, Boynton $\mathrm{MH}$, Pepper JK, et al. Public understanding of cigarette smoke constituents: three US surveys. Tob Control. 2016;26(5). doi:10.1136/tobaccocontrol-2015-052897
2. Kibet J, Kurgat C, Limo S, Rono N, Bosire J. Kinetic modeling of nicotine in mainstream cigarette smoking. Chem Cent J. 2016;10(60). doi:10.1186/s13065-016-0206-8

3. Zurabashvili D, Parulava G, Shanidze L, Kikalishvili B, Nikolaishvili M. THE LEVEL OF BENZ(A) PIREN IN TOBACCO SMOKE. Georgian Med News. 2016;(254):107-111.

4. Tilp C, Bucher H, Haas H, Duechs MJ, Wex E, Erb KJ. Effects of conventional tobacco smoke and nicotinefree cigarette smoke on airway inflammation, airway remodelling and lung function in a triple allergen model of severe asthma. Clin Exp Allergy. 2016;46(7):957-972. doi:10.1111/cea.12665

5. Bardach AE, Caporale JE, Alcaraz A, Augustovski F, Huayanay-Falconí L, Loza-Munarriz C. Burden of smoking-related disease and potential impact of cigarette price increase in Peru. Rev Peru Med Exp Salud Publica. 2016;33(4):651-661. doi:10.17843/rpmesp.2016.334.2548

6. World Health Organization. Tobacco [EB/OL]. http:// www.who.int/topics/tobacco/zh/. Accessed February 12, 2017.

7. Pérez de Isla L, Alonso R, Mata N, Saltijeral A, Muñiz O, Rubio-Marin P, et al. Coronary Heart Disease, Peripheral Arterial Disease, and Stroke in Familial Hypercholesterolaemia: Insights From the SAFEHEART Registry (Spanish Familial Hypercholesterolaemia Cohort Study). Arterioscler Thromb Vasc Biol. 2016;36(9):20042010. doi:10.1161/atvbaha.116.307514

8. World Health Organization. Tobacco Fact Sheet No. 339 [EB/OL]. http://www.who.int/mediacentre/factsheets/ fs339/zh/. Accessed February 12, 2017.

9. Raghuveer G, White DA, Hayman LL, Woo JG, Villafane J, Celermajer D, et al. Cardiovascular Consequences of Childhood Secondhand Tobacco Smoke Exposure: PrevailingEvidence, Burden, and Racial and Socioeconomic Disparities: A Scientific Statement From the American Heart Association. Circulation. 2016;134(16):e336-e359. doi:10.1161/cir.0000000000000443

10. Christen AG, Cooper KH. Strategic withdrawal from cigarette smoking. CA Cancer J Clin. 1979;29(2):96-107. doi:10.3322/canjclin.29.2.96

11. Roys M, Weed K, Carrigan M, MacKillop J. Associations between nicotine dependence, anhedonia, urgency and smoking motives. Addict Behav. 2016;62:145-151. doi:10.1016/j.addbeh.2016.06.002

12. Besson M, Guiducci S, Granon S, Guilloux JP, Guiard B, Repérant C, et al. Alterations in alpha5* nicotinic acetylcholine receptors result in midbrain - and hippocampus-dependent behavioural and neural impairments. Psychopharmacology. 2016;233(18). doi:10.1007/s00213-016-4362-2

13. Westmaas JL, McDonald B, Portier K. Topic Modeling of Smoking - and Cessation-related Posts to the American Cancer Society's Cancer Survivor Network 
(CSN): Implications for Cessation Treatment for Cancer Survivors Who Smoke. Nicotine Tob Res. 2017;19(8). doi:10.1093/ntr/ntx064

14. Pirie K, Peto R, Reeves GK, Green J, Beral V. The 21 st century hazards of smoking and benefits of stopping: a prospective study of one million women in the UK. The Lancet. 2012;381(9861). doi:10.1016/S0140-6736(12)61720-6.

15. Fernández E, Fu M, Pérez-Ríos M, Schiaffino A, Sureda X, López MJ. Changes in secondhand smoke exposure after smoke-free legislation (Spain, 2006-2011). Nicotine Tob Res. 2017;19(11). doi:10.1093/ntr/ntx040

16. Feirman SP, Glasser AM, Rose S, Niaura R, Abrams DB, Teplitskaya L, et al. Computational Models Used to Assess US Tobacco Control Policies. Nicotine Tob Res. 2017;19(11). doi:10.1093/ntr/ntx017

17. Schoenberg NE, Studts CR, Shelton BJ, Liu MA, Clayton R, Bispo J, et al. Randomized controlled trial of a faith-placed, lay health advisor delivered smoking cessation intervention for rural residents. Prev Med Rep. 2016;3:317-323. doi:10.1016/j.pmedr.2016.03.006

18. Chang YY, Yu SM, Lai YJ, Wu PL, Huang KC, Huang $\mathrm{HL}$. Improving smoking cessation outcomes in secondary care: Predictors of hospital staff willingness to provide smoking cessation referral. Prev Med Rep. 2016;3:229-233. doi:10.1016/j.pmedr.2016.02.002

19. JiangB,HeY,ZuoF, WuL,LiuQH,ZhangL,etal.Effectiveness of bupropion and counseling for smoking cessation. Zhonghua Yu Fang Yi Xue Za Zhi. 2016;50(7):640-644. doi:10.3760/cma.j.issn.0253-9624.2016.07.015

20. Hughes JR, Stead LF, Hartmann-Boyce J, Cahill K, Lancaster T. Antidepressants for smoking cessation. Cochrane Database of Systematic Reviews. 2014;(1). doi:10.1002/14651858.cd000031.pub4

21. Ussher MH, Taylor AH, Faulkner GE. Exercise interventions for smoking cessation. Cochrane Database of Systematic Reviews. 2014;(8). doi:10.1002/14651858.cd002295.pub5

22. Hajek P, Stead LF. Aversive smoking for smoking cessation. Cochrane Database of Systematic Reviews. 2001. doi:10.1002/14651858.cd000546.pub2

23. Hartmann-Boyce J, Cahill K, Hatsukami D, Cornuz J. Nicotine vaccines for smoking cessation. Cochrane Database of Systematic Reviews. 2012. doi:10.1002/14651858.CD007072.pub2

24. Barnes J, Dong CY, McRobbie H, Walker N, Mehta M, Stead LF. Hypnotherapy for smoking cessation. Cochrane Database of Systematic Reviews. 2010. doi:10.1002/14651858.CD001008.pub2

25. McRobbie H, Bullen C, Hartmann-Boyce J, Hajek P. Electroniccigarettesfor smoking cessation andreduction. Cochrane Database Syst Rev. 2014;(12):CD010216. doi:10.1002/14651858.CD010216.pub2

26. Stead LF, Koilpillai P, Lancaster T. Additional behavioural support as an adjunct to pharmacotherapy for smoking cessation. Cochrane Database of Systematic
Reviews. 2015. doi:10.1002/14651858.cd009670.pub3

27. Cahill K, Lindson-Hawley N, Thomas KH, Fanshawe TR, Lancaster T. Nicotine receptor partial agonists for smoking cessation. Cochrane Database of Systematic Reviews. 2016. doi:10.1002/14651858.cd006103.pub7

28. Stead LF, Perera R, Bullen C, Mant D, HartmannBoyce J, Cahill K, et al. Nicotine replacement therapy for smoking cessation. Cochrane Database of Systematic Reviews. 2012. doi:10.1002/14651858.cd000146.pub4

29. Bornemann P, Eissa A, Strayer SM. Smoking cessation: What should you recommend? J Fam Pract. 2016;65(1):22-29B.

30. van de Graaf RC, van Schayck OC. Helping people to give up smoking; efficacy and safety of smoking cessation interventions. Ned Tijdschr Geneeskd. 2017;161:D1131.

31. Wadgave U, Nagesh L. Nicotine Replacement Therapy: An Overview. Int J Health Sci (Qassim). 2016;10(3):425-435.

32. Lawvere S, Mahone MC, Cummings KM, Kepner JL, Hyland A, Lawrence DD, et al. A Phase II study of St. John's Wort for smoking cessation. Complementary Therapies in Medicine. 2006;14:175-184. doi:10.1016/j.ctim.2006.01.007

33. Breivogel B, Vuthaj B, Krumm B, Hummel J, Cornell D, Diehl A. Photoelectric Stimulation of Defined Ear Points (Smokex-Pro Method) as an Aid for Smoking Cessation: A Prospective Observational 2-Year Study with 156 Smokers in a Primary Care Setting. Eur Addict Res. 2011;17:292-301. doi:10.1159/000329717

34. Yang JS. Acupuncture and moxibustion eliminates withdrawal symptoms. Chinese Journal of Traditional Chinese Medicine. 2014;5(4):1-3.

35. Bai L, RenBQ. Influence of acupuncture at Ren quai smoking area on cotinine content. Modern Rehabilitation. 2001;5(2):144.

36. Cottraux JA, Harf R, Boissel JP, Schbath J, Bouvard M, Gillet J. SMOKING CESSATION WITH BEHAVIOUR THERAPY OR ACUPUNCTURE-A CONTROLLED STUDY. Behav. Res. Ther. 1983;21(4):417-424. doi:10.1016/0005-7967(83)90011-6

37. White AR, Resch KL, Ernst E. Randomized trial of acupuncture for nicotine withdrawal symptoms. Arch Intern Med. 1998;158:2251-2255. doi:10.1001/archinte.158.20.2251

38. Clavel F, Paoletti C, Benhamou S. Smoking Cessation Rates 4 Years after Treatment by Nicotine Gum and Acupuncture. Preventive Medicine. 1997;26:25-28. doi:10.1006/pmed.1996.9997

39. Wu Y. Clinical efficacy observation of acupuncture for smoking cessation. [master's thesis]. Chinese Academy of Traditional Chinese Medicine; 2015.

40. Baccetti S, Monechi MV, Frè MD, Conti T, Faedda M, Panti $\mathrm{P}$, et al. Smoking cessation with counselling and Traditional Chinese Medicine (TCM): A randomized controlled trial. Acupuncture and Related Therapies. 2015;(3):48-54. doi:10.1016/j.arthe.2016.05.002

41. Wu YR. Analysis of 10 Cases of Smoking Cessation Using 
Acupuncture. Chinese Journal of Traditional Chinese Medicine. 1980;(5):48-49.

42. Steiner RP, Hay DL, Davis AW. Acupuncture Therapy for the Treatment of Tobacco Smoking Addition. American Journal of Chinese Medicine.1982;(4):107-121. doi:10.1142/s0192415x82000178

43. Ter Riet G, Kleijnen J, Knipschild P. A meta- analysis of studies into the effect of acupuncture on addiction. British Journal of General Practice. 1990;40:379-382.

44. Lambert C, Berlin I, Lee TL, Hee SW, Tan AS, Picard D, et al. A Standardized Transcutaneous Electric Acupoint Stimulation for Relieving Tobacco Urges in Dependent Smokers. Evidence-Based Complementary and Alternative Medicine. 2011:8. doi:10.1093/ecam/nen074

45. Liu AH, Meng XH. 100 cases with the Chinese medicine Help to Quit Smoking. Chinese Medicine Distance Education of China.2014;15(12):128-129.

46. White AR, Rampes H, Liu JP, Stead LF, Campbell J. Acupuncture and related interventions for smoking cessation. Cochrane Database of Systematic Reviews. 2014. doi:10.1002/14651858.cd000009.pub4

47. Liu Jian-Ping. The Composition of Evidence Body of Traditional Medicine and Recommendations for Its Evidence Grading. Chinese Journal of Integrated Traditional and Western Medicine. 2007;27(12):1061-1064.

48. van Haselen RA, Friedrich ME. A comprehensive assessment of the role of complementary and alternative medicine in smoking cessation. Perfusion. 2003;16(10):1-6.

49. Liu Z, Wang YY, Wu Y, Yang JS. Condition and effectiveness evaluation of acupuncture for smoking cessation. Chinese Acupuncture \& Moxibustion. 2015;35(8):851-857.

50. Tahiri M, Mottillo S, Joseph L, Pilote L, Eisenberg MJ. Alternative smoking cessation aids: a metaanalysis of randomized controlled trials. The American Journal of Medicine. 2012;125(6):576-584. doi:10.1016/j.amjmed.2011.09.028

51. Ashenden R, Silagy CA, Lodge M, Fowler G. A metaanalysis of the effectiveness of acupuncture in smoking cessation. Drug and Alcohol Review. 1997;16:33-40. doi:10.1080/09595239700186311

52. Baillie AJ, Mattick RP, Hall W, Webster P. Metaanalytic review of the efficacy of smoking cessation interventions. Drug and Alcohol Review. 1994;13:157170. doi:10.1080/09595239400185231

53. Di YM, May BH, Zhang AL, Zhou IW, Worsnop C, Xue CCL. Ear-acupuncture, ear-acupressure and auriculotherapy for cigarette smoking cessation. Drug and Alcohol Dependence. 2014;142:14-23.

54. Kim SS, Chen W, Kolodziej M, Wang X, Wang VJ, Ziedonis D. A systematic review of smoking cessation intervention studies in China. Nicotine \& Tobacco Research. 2012;14:891-899. doi:10.1093/ntr/ntr289

55. Kitikannakorn N, Chaiyakunapruk N, Nimpitakpong P, Dilokthornsakul P, Meepoo E, Kerdpeng W. An overview of the evidences of herbals for smoking cessation.
Complementary Therapies in Medicine. 2013;21:557564. doi:10.1016/j.ctim.2013.08.006

56. Linde K, Vickers A, Hondras M, ter Riet G, Thormählen J, Berman B, et al. Systematic reviews of complementary therapies-an annotated bibliography. Part 1: acupuncture. BMC Complementary and Alternative Medicine. 2001;1:3.

57. White AR, Resch KL, Ernst E. Smoking cessation with acupuncture? A 'best evidence synthesis'. Forsch Komplementarmed. 1997;4:102-105. doi:10.1159/000210305

58. Cheng HM, Chung YC, Chen HH, Chang YH, Yeh ML. Systematic review and meta-analysis of the effects of acupoint stimulation on smoking cessation. The American Journal of Chinese Medicine. 2012;40(3):429-442. doi:10.1142/s0192415x12500334

59. White A, Moody R. The effects of auricular acupuncture on smoking cessation may not depend on the point chosenan exploratory meta-analysis. Acupuncture in medicine. 2006;24(4):149-156. doi:10.1136/aim.24.4.149

60. White AR, Resch KL, Ernst E. A meta-analysis of acupuncture techniques for smoking cessation. Tobacco Control. 1999;8:393-397. doi:10.1136/tc.8.4.393

61. White AR, Rampes H, Ernst E. Acupuncture for smoking cessation. The Cochrane Database of Systematic Reviews. 2002;(2):CD000009.

62. White AR, Rampes H, Campbell J. Acupuncture and related interventions for smoking cessation. Cochrane Database of Systematic Reviews. 2006;(1):CD000009.

63. White AR, Rampes H, Liu JP, Stead LF, Campbell J. Acupuncture and related interventions for smoking cessation. Cochrane Database of Systematic Reviews. 2011;(1):CD000009. doi: 10.1002/14651858.CD000009.pub3

CONFLICTS OF INTEREST

Each of the authors has completed and submitted an ICMJE form for disclosure of potential conflicts of interest. The authors declare that they have no competing interests, financial or otherwise, related to the current work.

\section{FUNDING}

This work was supported by the Youth Research of Liaoning Economic and Social Development of Social Science Association of Liaoning Province (2017/slktqn-085) and the Youth Project of Humanities and Social Science Research of Department of Education in Liaoning Province (L201731). Jian-Ping Liu was partially supported by the grant number R24 AT001293 from the National Center for Complementary and Alternative Medicine of USA. The funders had no role in study design, data collection and analysis, writing the manuscript, decision to publish, or preparation of the manuscript.

\section{PROVENANCE AND PEER REVIEW}

Not commissioned; externally peer reviewed 